ISSN: 2162-3104 Print/ ISSN: 2166-3750 Online

Volume 8, Issue 4 (2018), pp. 1736-1747

(C) Journal of International Students

http://jistudents.org/

doi: $10.5281 /$ zenodo. 1468078

\title{
Studying in Canada: Experiences of Female Graduate Students from Saudi Arabia
}

\author{
Bushra Alqudayri \\ University of Victoria, Canada \\ Tatiana Gounko \\ University of Victoria, Canada
}

\begin{abstract}
This paper presents findings from a study which explored experiences of Saudi Arabian female graduate students studying in Canada. The data for this descriptive qualitative study was collected through semi-structured interviews with ten students undertaking graduate studies in universities across 5 Canadian provinces. The findings of this study suggest that female graduate students from Saudi Arabia face unique challenges related to adaptation to a new education environment and to managing cultural expectations of Saudi and Canadian communities. Studying and living in Canada affected our participants' personal values and changed the way they viewed themselves, their culture and community.
\end{abstract}

Keywords: Canadian universities, gender segregation, international students, Saudi Arabia

Global student mobility is a growing trend. Over the past decade, between 2004 and 2014, the number of international students studying in Canada has doubled. Moving across the world for education can be both exciting and stressful for students. Many international students face various challenges arising from leaving their family and friends and getting used to new cultures and academic settings. However, students from Saudi Arabia experience unique challenges as they transition from a conservative gender-segregated environment to a liberal gender-mixed environment. Saudi Arabia is distinctive in many ways; the most prominent difference that distinguishes Saudi Arabia from many other countries is a strict gender segregation practiced in most public areas including schools and universities. Saudi women are subjected to numerous restrictions affecting their daily life. One such restrictions, known as the male guardian policy, requires that a woman be accompanied by a man (father, brother, or husband) at all times. When Saudi female students travel abroad to study in Western universities, they also have to be accompanied by a male guardian. While some Saudi students stay in Canada for a short period of time, many spend several years completing their graduate degrees. During these years, they will invariably deal with various issues arising from their customary and new cultural experiences. 
In 2005, King Abdullah bin Abdul Aziz of Saudi Arabia issued a royal decree for the establishment of a national scholarship program to provide opportunities for Saudi citizens to study abroad. The stated aim of the program was: "For them [Saudi Arabians] to know the world and for the world to know them" (Estimo, 2014). The main objective of the King Abdullah Scholarship Program (KASP) was to meet the national needs for a professionally and academically prepared workforce that could compete at an international level. In the last several years, the number of Saudi students studying abroad has increased significantly. Current statistics from the Saudi Ministry of Education (2017) indicate that 5,165, or 42 per cent of all Saudi students, are female students undertaking doctoral degrees in western universities. The Saudi society can see the social and cultural impact of this massive outbound student movement (Ahmed, 2015). As Saudi students return home, they bring new ideas and promote change in the Kingdom. Despite the increasing numbers of Saudi Arabian students in Canadian universities, the literature regarding experiences of Saudi female graduate students in Canada is limited.

The purpose of this qualitative study was to examine experiences of female graduate students from Saudi Arabia attending Canadian universities. We wanted to find out how these students describe their experiences of being exposed to Canadian academic methods and cultural and social norms in a mixed-gender Canadian society that is so distinct from their home country. The research questions asked in this inquiry were: How do students describe their academic and personal experience in Canada? What challenges, if any, did they encounter during their graduate programs? To respond to these general research questions we employed a social constructivist perspective based on the assumption that individuals seek understanding and develop subjective meanings of the world in which they live and work. The goal of such research is to rely as much as possible on the participants' views of the situation being studied (Creswell, 2014).

\section{Gender Segregation in Saudi Arabia}

The Kingdom of Saudi Arabia was established by Abdul Aziz bin Saud on September 23, 1932. Since then, the country has been experiencing a conflict between tradition and modernization as well as balancing between Islamic values, modern developments and cultural customs. The Wahhabi interpretation of Islam is the country's state sponsored religion (CNN, 2017). Saudi Arabia is a patriarchal society with distinct gender roles: men are expected to be responsible for providing a secure life for their family members whereas women are expected to care for the family. This gender role distinction is dictated mainly by the religious and cultural practices in Saudi Arabia. These practices enforce strict gender segregation which is evident in almost every public and private institutional setting. According to Alhazmi and Nyland (2013), gender segregation is central to most people's social, educational, economic and political activities; it is also a significant contributor in forming a Saudi cultural identity. As a result of such rigidly defined gender roles, many restrictions are imposed on women in the Saudi society, including the need to keep away from any man who is not a family member. Women of Saudi Arabia have fewer rights than men and play a very limited role in public life.

For many years, Saudi women and activists have been campaigning to abolish the male guardian system. In April 2017, King Salman issued an order to all government agencies stating that women should not be denied access to government services because they do not have a male guardian's consent, unless existing regulations require it. Government agencies 
were asked to provide a list of procedures that would require a male guardian approval. Despite this welcome change, some experts believe that the King's order will have a limited impact unless the authorities finally act deliberately and end this discriminatory system once and for all (Human Rights Watch, 2017).

On September 26, 2017, another long awaited decree was issued by the King. According to the decree Saudi women will be able to drive cars in June 2018. Saudi Arabia is the only world nation that does not allow women to drive a car. Even though no formal law banned women from driving, they generally could not obtain driving permits. The Saudi women and activists consider this a landmark moment for a society where gender roles are "rigidly demarcated and strictly enforced" (Chulov \& Al-Faour, 2017).

\section{EXPERIENCES OF SAUDI INTERNATIONAL STUDENTS}

Over the years, researchers have empirically examined and discussed experiences of and challenges faced by international students. The most significant challenges affecting international students relate to: general living adjustment, academic adjustment to a new university system, sociocultural adjustment to different cultural norms and behaviors, and personal psychological adjustment (Tseng \& Newton, 2002; Hyun et al., 2007; Wenhua \& Zhe, 2013). The difficulty of coping with some psychological challenges such as homesickness and loneliness may be compounded by limited financial resources, immigration policies in relation to student visas and employment and cultural differences. International students are also less likely to seek support from health services due to an unawareness of mental health issues and the cultural stigma around mental health problems (Gounko, 2018).

A number of researchers (e.g., Alsahafi \& Seong-Chul, 2017; Alhazmi \& Nyland, 2013; Fallon \& Bycroft, 2009; Hamad, 2012; Heyn, 2013; Midgley, 2009a, 2009b; Shaw, 2010) specifically examined experiences of international students from Saudi Arabia using both qualitative and quantitative approaches. These studies concluded that studying English and using English for academic purposes was the greatest challenge facing Saudi international students. Many interviewed students stated that they encountered difficulties during oral presentations, discussions, writing papers, taking exams, and speaking to peers and professors in English. Students' perceptions about their adjustment to the English language environment depended on their age, gender, marital status and area of study.

In addition to the problems with the English language, researchers also identified other difficulties related to the cross-cultural impact of students' values and cultural identity (e.g., Alsahafi \& Seong-Chul, 2017, Heyn, 2013; Shaw, 2010; Alhazmi \& Nyland, 2010). For examples, Saudi students who lived abroad for an extended period of time expressed values similar to their host culture. They held more liberal views compared to the Saudi students studying in Saudi Arabia. These students were also more inclined to support women's rights in Saudi Arabia (Heyn, 2013) and perceived themselves independent and resilient after having adjusted to a mixed-gender environment (Alhazmi \& Nyland, 2013). According to Berry (2008), gender has an impact on acculturation into the new society where women are sometimes at a higher risk during the acculturation process. When women who come from the countries where females are treated significantly differently, as in Saudi Arabia, these women's attempts to take on new roles available in the society of settlement may bring them into conflict with their heritage culture.

A small group of studies focused specifically on experiences of female Saudi students studying in western universities in the United States and Australia. For example, Kampman 
(2011) described educational experiences of female students and challenges of traversing Western and Middle Eastern educational paradigms. Notwithstanding the challenges, Clerehan, McCall, McKenna and Alshahrani (2012) reported that, graduate students from Saudi Arabia (both male and female) undertaking studies in Australia experienced a transformational change: their change was intellectual, psychological and developmental.

\section{RESEARCH METHOD}

To examine the lived experiences of the female Saudi graduate students in Canadian universities we chose a qualitative descriptive study (Miles \& Huberman, 1994). Using purposeful sampling, we recruited 10 female Saudi Arabian graduate students currently studying in Canadian universities. We aimed at eliciting students' accounts of their experience in Canada and attempted to capture participants' descriptions from a fresh perspective without any preconceived assumptions (Creswell, 2007).

\section{Setting and Participants}

Our participants ranged from 24 to 32 years of age and were enrolled in graduate programs, PhD (1 participant) and Master's degrees ( 9 participants), in sciences and humanities. By the time of the interviews, our participants had spent more than one year in Canada. All participants were accompanied by a male guardian; unmarried participants were accompanied by their fathers and/or brothers, whereas married participants were accompanied by their husbands. Several participants got married while completing their programs in Canada. They were first accompanied by their brothers and/or fathers and, later, by their husbands. A brief description of our participants is presented in Table 1.

Table 1. Characteristics of the participants.

\begin{tabular}{lcccc}
\hline Pseudonym & Degree & Male Guardian & $\begin{array}{c}\text { Number of } \\
\text { Children }\end{array}$ & Age \\
\hline Suha & Doctorate & Father, brother, husband & None & 28 \\
Seba & Master's & Brother & None & 26 \\
Tala & Master's & Husband & 1 & 25 \\
Noor & Master's & Husband & None & 31 \\
Marwa & Master's & Father, brother & None & 26 \\
Lama & Master's & Brother & None & 24 \\
Maria & Master's & Brother, husband & None & 25 \\
Salma & Master's & Brother & None & 27 \\
Farah & Master's & Husband & 1 & 32 \\
Balqees & Master's & Father, brother, husband & None & 30 \\
\hline
\end{tabular}

\section{Data Collection}

Semi-structured interviews with the study participants contained questions about students' backgrounds, education and life experiences in Canada. We asked the participants about their academic programs, interactions with other students, future plans, and their life in Canada. The interview questions were informed by the review of the literature on international student experiences, adaptation and challenges, and our own involvement with international students from Saudi Arabia. The interviews were both face-to-face and via Skype and generally lasted 
for sixty to ninety minutes. Most of the interviews were conducted in Arabic because the participants felt it would be easier and more comfortable to express themselves in their own language. Only one participant preferred to speak English during her interview. All Arabic language interviews were recorded, transcribed verbatim and then translated into English. Copies of the transcripts in Arabic and English were emailed to the participants in order to receive their feedback and ensure accuracy of their responses. Some participants made minor changes in the original interview transcripts, which we then incorporated in the final version of the transcripts.

\section{Ethical Considerations}

Prior to conducting the study, we applied and received a University of Victoria Ethics Approval. After identifying potential participants, we initially sent invitations via email to 14 graduate students. We received responses from 10 students who agreed to participate in the study. The participants were informed that all possible steps would be taken to protect their identities and that they could withdraw at any time during the study. Prior to the data analysis and final report, we assigned pseudonyms to our participants to ensure anonymity. All 10 interviewed graduate students were enthusiastic about their involvement in this study.

\section{Data Analysis}

During the analysis process, we sought to answer the following research questions: (1) How do students describe their academic and personal experience in Canada? and (2) What challenges, if any, did they encounter during their graduate programs?

After reading and re-reading the interviews, the researchers analysed the data independently. Initially, the data were coded using summarized words and short texts of the participants, which were grouped into two major domains. The first domain related to students' academic experience; the second one - to their personal experiences of living in Canada. These two domains were further subdivided into themes, some of which overlapped. The short texts were reorganized several times until they formed coherent thematic groupings.

Our analysis of the interviews revealed a number of different themes related to the experiences of Saudi female graduate students studying in Canadian universities. These themes include adapting to new teaching and learning styles, mixed-gender setting, negotiating Canadian and Saudi cultural expectations, reevaluating existing cultural norms of the Saudi community.

\section{THE IMPACT OF STUDYING IN CANADA}

All study participants received scholarships from the Saudi government to complete graduate degrees in Canada. Some participants were expected to pursue a doctorate degree after finishing master's degrees. By the time of the interviews, all ten students had spent more than 12 months in Canada. The participants expressed willingness to participate in this research study; they considered this an opportunity to share their experiences, reflect on their personal changes, and inform future female students from Saudi Arabia. The analysis revealed two major domains discussed by the participants: challenges of studying at a graduate level in a Western country and changes in personal attitudes towards Canadian and Saudi Arabian cultures. Within these domains, several major themes appeared in each interview and across interviews. The following findings represent a portion of the data analysis. We provide many examples of participants' quotes to illustrate the themes that emerged through the analysis. 


\section{Academic Challenges}

Our participants were eager to share their experiences of studying in Canadian universities and to describe the challenges that they faced while adjusting to a new academic and public culture. All ten participants identified several academic challenges experienced during the first year of their graduate programs. These academic challenges included difficulties with academic English and writing, understanding the differences between Canadian and Saudi Arabian education methods and requirements, and learning about new approaches to study.

Although English was a second language for all participants in this study, only six of them reported experiencing difficulties with academic English and writing during their classes. For example, Noor stated that "The first challenge is the [English] language. They [teaching faculty] try to evaluate you as a native speaker. So the language is the biggest barrier for me."

Since all the participants of this study had completed their bachelor degrees in Saudi Arabia, they acknowledged experiencing difficulties during the initial transition and adaptation to the Canadian higher education system, its methods and requirements. Several participants specifically talked about their adjustment to a mixed-gender education environment. One example stands out in this discussion. Lama's experience differed significantly from all the other participants' because she was pursuing a degree in engineering which is a predominantly male dominated field of study in both Saudi Arabia and Canada. This is how she described the commencement of her Master's program in Canada:

I did not imagine I would be the only female. It was a very difficult experience to accept a sudden change, getting used to another culture and to be alone in a male dominated department. ... I was the only female in my first 3 courses. I remember, I was scared to walk into the building and to look at people's faces. I think, when I first came here, my personality was different and created many challenges for me, such as accepting a new culture and getting used to being the only Saudi female studying Engineering. I did not know that so few women in Canada would study Engineering.

For Saudi females students used to living and studying in a gender segregated environment, studying in mixed-gender universities was clearly challenging at first. For some, the presence of male classmates, as in Lama's case, was a source of discomfort and "a difficult experience."

Studying in graduate programs in Canada also made some participants reevaluate their previous education and work experiences. For instance, Marwa's "Organizational Behavior" course "had the biggest influence" on her. She explained that she learned about "the employees' rights, and how the organizations support and encourage their employees to be better and more productive persons." This course made her feel like "a slave during [her] previous work experience" in Saudi Arabia. Comparing the two experiences, Marwa said that she felt that in the West and in Canada, people seemed to receive recognition and encouragement from managers and co-workers, and, unlike in Saudi Arabia, their contribution was appreciated.

Our participants consistently acknowledged that academic programs and pedagogical approaches in Canadian universities differed from education practices in Saudi Arabian institutions. Comparing her Canadian education experience to her studies in Saudi Arabia, Lama stated that:

Education in Saudi Arabia is nothing compared to Canadian. I mean, I studied in ... university, majoring in physics. We did not have any projects. ...It was all pure 
theory. No chance to expand your horizon and acquire profound knowledge. Here, I have taken courses that go really deep into new technologies, etc.

Most of the participant were accustomed to teacher-centered approaches and had to adjust to, as they described, "more independent" and "self-reliant" learning in Canada. They had to acquire new study habits, learn how to engage with their peers and professors, and balance their family life with academic demands. This was especially challenging for two of our participants who were already raising children.

\section{Social and Cultural Challenges}

Many participants reported experiencing personal challenges while adapting to a new environment in Canada. They openly discussed social and cultural issues they had to grapple with while learning about and adjusting to Canadian life and customs. Several of our participants acknowledged, and some of them even openly criticized, difficulties with members of the Saudi community they encountered during their studies. The participants related these difficulties to existing Saudi Arabian cultural norms and expectations that required women to behave in certain ways.

Studying and living in a mixed gender environment made some of our participants question established cultural norms of Saudi Arabia and Canada. For example, Salma, shared her disappointment with certain Saudi students she had met during her preparatory English program in Canada. She believed that "the same judgmental culture has moved from Saudi Arabia to Canada."

Although I did not have a problem with a mixed gender class because I studied Nursing in Saudi Arabia and did my internship in a hospital, I felt that I was being constantly watched. Honestly, I felt that the Saudi guys were watching every movement every Saudi girl made. ... If the Saudi guys saw me talking to other male classmates, they would accuse me of lacking shyness (hayaa). ... As a result, I created a wall between myself and the Saudi guys.

Our participants observed that men constituted a majority of Saudi Arabian students studying in Canada. These female students felt that existing gender segregation policies in their country created a sense of discomfort among Saudi Arabian students in a mixed gender Canadian society. Many participants described how this cross-cultural experience of studying and living in Canada changed their perceptions and even long held values. Several of our participants questioned the cultural norms existing in their community. For example, Salma who was outspoken about her personal experiences described how living in Canada caused "contradictions within herself." In the beginning, she tried "to behave according to what is right and what is wrong according to the Saudi tradition." She would not talk to foreign males, which, in her opinion, was a Saudi Arabian cultural norm. Salma added that behaving according to the Saudi Arabian cultural norms in the Canadian context made her feel "less honest."

This is how another participant, Lama, described her uneasiness with meeting Saudi Arabian males off campus:

I believe that I should not communicate with them. I cannot deny that I was forced to talk to the Saudis due to some course requirements. But when I unexpectedly met them off campus, I would pretend that I didn't know them. 
Another participant discussed her personal struggle with and attempts to reconcile cultural norms and conduct expected from female students by the Saudi community and those practiced in Canada. Balqees stated that she used to take things for granted, unquestionably following the existing cultural and religious norms of her home country which, according to her, were based on the Islamic teachings.

Studying abroad made me look back at my country and its practices as an outsider with a critical perspective. I realized that some traditional and historical practices are valued and seen as Islamic principles. For example, many restrictions are imposed on a Saudi woman, such as wearing a veil that covers her face, in the name of Islam. Neither the Quran, nor the Prophet's narration state that a woman must cover her face.

Perhaps, the most expressive account of questioning the traditional cultural norms came from Marwa. This is how she described her first reaction upon arriving in Canada. "I heard there was racism in Canada, but once I landed here, I discovered that it is us who are racists, not them [Canadians]."

When I first came to Canada, the Canadian culture did not influence me, yet I had a cultural shock. This cultural shock was not from the Canadian culture, but from my own culture. I don't want to hurt anyone, but I began to disrespect my culture. I feel that it's fake, and people are liars and hypocrites - all of them.

While Marwa's case may be unique, other participants also acknowledged that they too were changed by the experience of studying and living in Canada. They felt that their personal beliefs and values had changed; they had started questioning Saudi cultural norms and traditions. Several participants reported that their perceptions about women's roles in society were not the same anymore. Specifically, they emphasized that women should not be viewed as passive bystanders, rather they should be treated as capable, independent, and responsible as men in their society. Moreover, some students stated that Saudi women should be emancipated from the Saudi traditional values which were discriminatory and predominantly favored men. Several participants expressed a strong desire for independence and personal freedom. This is how Marwa articulated her views about the existing male guardianship policy: "I have become more independent [in Canada] and have more freedom now. I mean, today, I can travel by myself and do whatever pleases me, without asking anyone's permission. I have become more confident and bolder than ever before."

It was surprising to learn that some study participants experienced a sense of discomfort being around their compatriots regardless of their gender. Although the level of discomfort varied, five participants stated that they had experienced feeling "uneasy" and "anxious" around other Saudis. Two participants were particularly outspoken when they described their experiences. For example, Marwa reported that at Concordia University, she had had "a very bad experience" with many Saudi friends. Later, when she had moved to another university to continue her graduate program, she had decided not to engage with the Saudi community in the new city. She felt that the Saudis were "liars and hypocrites." Another participant, Seba, shared that she too had had difficulties in finding a good group of friends among the Saudis. Stating the importance of having close relationships with friends while studying abroad, she said she had eventually found good friends among the Arabs raised in Canada. 
Two other participants, Tala and Salma, spoke openly about their negative experiences with the Saudi community. Tala's personal discomfort with the Saudi community had resulted from her not wearing a hijab. She reported that,

Before coming to Canada, I was afraid that I would face discrimination and racism. Honestly, I have been mistreated not by the Canadians, but by the Arabs. It is the Arabs who are prejudiced and believe that 'she doesn't cover her hair, she has neither values, nor religion.' When I decided not to wear a hijab, I was afraid of the Canadians, but, surprisingly, the negative reaction and mistreatment came from the fellow Arabs.

In Salma's opinion, "the same judgmental culture has moved from Saudi Arabia to Canada." She expressed her anxiety around male Saudi students, "Sometimes, I heard them talk negatively about other girls, which made me mad; I was pretty sure I was one of those girls as well. The "judgmental nature of the Saudi culture" made her uncomfortable and uncertain about her own behavior in Canada.

Later, I started to change. I thought that we, the Saudi people, should stick together and be like brothers and sisters. Unfortunately, the Saudi females, especially those who were married, did not like this and started keeping their distance from me for being "so liberal."

Concluding her story, Salma stated that, at a certain point, she had decided that she would live her life according to what she considered to be right.

\section{DISCUSSION}

Much of the literature on international student experiences focuses on various issues of adjustment to a new academic setting and transition processes. We expected that our participants would primarily talk about academic challenges addressed in the previous studies. To our surprise, the stories shared by our participants demonstrated the added complexity of the Saudi female students' experiences in Canada. Unlike other groups of international students, these graduate students come across unique challenges in Canada. Not only do these women have to negotiate cultural and religious expectations of their home country, such as being accompanied by a male family member during their studies abroad and following a specific dress code, they also have to adjust to secular mixed gender academic and public settings.

Previously, researchers noted that international students generally retain many features of their identity, especially when they interact formally or informally with their culture and community. Cultural identity corresponds to a set of beliefs individuals have about themselves influenced by their historical, cultural and religious context and includes the transmitted knowledge, beliefs, attitudes, values and traditions (Berry, 2008; Jameson, 2007; Alhazmi \& Nyland, 2013). Studying and living in Canada made our participants think about and, at times, question their beliefs and cultural norms. Most of the women related a number of personal incidents which had profoundly affected them and their views of the Saudi community. Several participants stated that they had changed in many ways; they had gained confidence and courage and had become more independent and self-reliant in Canada.

At the same time, questioning cultural expectations and existing gender roles made some of our participants feel at odds with other members of the Saudi community who either disapproved of our participants' behavior or accused them of being "too liberal." Several 
participants described the sense of discomfort they felt while dealing with the expectations of two distinct cultures - a patriarchal Saudi culture and a liberal Canadian culture. This sense of discomfort is caused by social, psychological, cultural, religious and political pressures the Saudi women have to deal with in their home country and while studying abroad (Razek \& Coyner, 2014). Our participants stated that gender segregation practices and the Saudi cultural norms and expectations caused much of the discomfort during their study in Canada.

Our findings support earlier research which suggested that traversing Western and Middle Eastern cultural values may bring women into conflict with their heritage culture (e.g., Kampman, 2011; Clerehan et al., 2012; Alhazmi \& Nyland, 2013). To a large extent, this conflict arises from a dominant social practice of gender segregation which plays an important part in forming cultural identity of the Saudi students.

The findings of this study highlight specific challenges experienced by female students who have to constantly navigate between Saudi religious and cultural expectations and Canadian academic and social environment. Gender segregation practices and cultural expectations within the Saudi community are important factors to consider when discussing experiences of Saudi female students. For the most part, our participants chose to follow and behave according to their traditional cultural norms. However, several students questioned the absolute rules imposed on them by Saudi Arabian society and the expectations of their compatriots in Canada. In our opinion, future research can provide further insight into the relationships within the Saudi campus community and how these relationships may affect students' overall experience of studying and living in Canada.

\section{CONCLUSIONS AND IMPLICATIONS}

The findings of this study suggest that female graduate students from Saudi Arabia face unique challenges when they come to Canada to pursue their education. Studying and living in Canada clearly affected our participants' personal values and changed the way they viewed themselves, their culture and community. Their stories revealed how gender segregation and cultural expectations became the cause of uneasiness for some of our participants as they engaged in educational and social activities in Canada. These findings add a new dimension to our understanding of educational experiences of female students who come from traditional patriarchal societies. Given that very few studies specifically address experiences of female students from Saudi Arabia, future research involving this group of students can provide further insight into the impact studying abroad has on the Saudi women.

\section{Limitations of the Study}

The findings of this qualitative study may not be generalized to experiences of other Saudi female graduate students in other settings as the data were collected from a small purposefully selected sample of ten female Saudi graduate students studying in Canadian universities. Larger qualitative or mixed method studies across Canadian universities could provide more detailed information about whether our findings are limited to this group of participants.

\section{REFERENCES}

Ahmed, M. (2015). Outward mobility of Saudi students: An overview. International Higher Education, $83,19-20$. 
Alhazmi, A., \& Nyland, B. (2010). Saudi international students in Australia and intercultural engagement: A study of transitioning from a gender segregated culture to a mixed gender environment. Paper presented at the International Education Conference of the ISANA: International Education Association, Melbourne, VIC, Australia.

Alhazmi, A., \& Nyland, B. (2013). The Saudi Arabian international student experience: From a gendersegregated society to studying in a mixed-gender environment. Compare. A Journal of Comparative and International Education, 43 (3), 346-365.

Alsahafi, N., \& Seong-Chul, S. (2017). Factors affecting the academic and cultural adjustment of Saudi international students in Australian universities. Journal of International Students, 7(1), 53-72.

Berry, J. W. (2008). Globalisation and acculturation. International Journal of Intercultural Relations, 32(4), 328-336.

Chulov, M., \& Al-Faour, N. (2017, September 27). "This is a huge step for us": Jubilation as Saudi women allowed to drive. The Guardian retrieved from https://www.theguardian.com/ world/2017/sep/27/huge-step-jubilation-saudi-arabian-women-allowed-to-drive

Clerehan, R., McCall, L., McKenna, L., \& AlShahrani, K. (2012) Saudi Arabian nurses' experiences of studying Masters degrees in Australia. International Nursing Review 59, 215-221.

CNN. (2017). Saudi Arabia fast facts. Retrieved June 13, 2017 from http://www.cnn.com/ 2015/04/01/middleeast/saudi-arabia-fast-facts/

Creswell, J. W. (2007). Qualitative inquiry and research design: Choosing among five approaches, 2nd edition. Thousand Oaks: Sage Publications.

Estimo, R. (2014). Scholarship schemes widen prospects for talented youngsters. Arab News. Retrieved from http://www.arabnews.com/news/555716

Fallon, F., \& Bycroft, D. (2009). Developing materials for homestays and students from Saudi Arabia. Paper presented at the ISANA International Education Association 20th International Conference. Retrieved from http://proceedings.com.au/isana2009/

Hamad, E. O. (2012). Personal constructs of Saudi Arabian graduate students studying at a large Canadian university: A personal construct theory approach. Unpublished master's thesis. The University of Western Ontario.

Heyn, M. E. (2013). Experiences of male Saudi Arabian international students in the United States. Unpublished doctoral dissertation. Western Michigan University.

Human Rights Watch. (2016). Boxed in. Retrieved from https://www.hrw.org/report/2016/07/16/ boxed/women-and-saudi-arabias-male-guardianship-system

Human Rights watch. (2017). As women driving ban ends. Retrieved from https://www.hrw.org/ news/2017/09/27/saudi-arabia-womens-driving-ban-ends-provide-parity

Hyun, J., Quinn, B., Madon, T., \& Lustig, S. (2007). Mental health need, awareness, and use of counseling services among international graduate students. Journal of American College Health, 56(2), 109-118.

Gounko, T. (2018). Mental health accommodation for graduate students. In W.T. Smale (Ed.), Perspectives on educational law and policy (pp. 395-412). Burlington, ON: Word \& Deed Publishing.

Jameson, D. A. (2007). Reconceptualizing cultural identity and its role in intercultural business communication. Journal of Business Communication, 44, 199-235.

Kampman, D. (2011). From Riyadh to Portland: The study abroad experiences of five Saudi Arabian female students. MA TESOL Collection 512. Retrieved from http://digitalcollections.sit. edu/ipp_collection/512

Midgley, W. (2009a). They are, he is, and I am: Different adjustment accounts of two male Saudi Arabian nursing students at an Australian university. Studies in Learning, Evaluation, Innovation and Development, 6(1), 82-97.

Midgley, W. (2009b). When we are at Uni our minds are at home: Saudi students worrying about wives. Paper presented at the ISANA International Education Association 20th International Conference, Queensland, Australia. 
Miles, M., \& Huberman, A. M. (1994). Qualitative data analysis: An expanded sourcebook (2nd ed. ). Thousand Oaks, CA: Sage.

Ministry of Education Statistics Centre. (2017). General statistics: Higher education. Retrieved from https://www.moe.gov.sa/en/Pages/default.aspx

Razek, N., \& Coyner, S. (2014). Impact of self-efficacy on Saudi students' college performance. Academy of Educational Leadership Journal, 18(4), 85-96.

Shaw, D. L. (2010). Bridging differences: Saudi Arabian students reflect on their educational experiences and share success strategies. Unpublished doctoral dissertation. Oregon State University, Corvallis, Oregon.

Tseng, W. \& Newton, F. B. (2002). International students' strategies for well-being. College Student Journal, 36(4), 591-597.

Wenhua, H., \& Zhe, Z. (2013). International students' adjustment problems at university: A critical literature review. Academic Research International, 4(2), 400-406.

BUSHRA ALQUDYARI, MEd, completed her master's degree in the Department of Educational Psychology and Leadership Studies, University of Victoria, Canada. She is currently working at the Victoria Immigrant and Refugee Centre Society in British Columbia, Canada. Email: bushra@vircs.bc.ca

TATIANA GOUNKO, $\mathrm{PhD}$, is an Associate Professor in the Department of Educational Psychology and Leadership Studies, University of Victoria, Canada. Her major research interests lie in the area of international and comparative higher education, policy and reform. Email: tgounko@uvic.ca 